Годищњ ак Филозофског̄ факулиетейа у Новом Саду, Кюиг̄a ХХХVIII (2013)

Annual Review of the Faculty of Philosophy, Novi Sad, Volume XXXVIII (2013)

Vladimir Barović

Filozofski fakultet Univerziteta u Novom Sadu

UDK 316.774:323.285

323.285:070

Originalni naučni rad

\title{
POLAZNI ELEMENTI ZA MEDIJSKO IZVEŠTAVANJE O TERORIZMU KAO OBLIKU KRIZNE SITUACIJE*
}

U radu je definisan termin terorizam sa medijskog aspekta i izneti su osnovni elementi koji utiču na medijsko izveštavanje o tom globalnom fenomenu. Markirana je podela terorističkih organizacija po osnovnim kriterijumima, ukazano je na njihove motive i načinjena distinkcija između klasičnog kriminala i terorizma. U radu su izneti osnovni elementi koji utiču na nastanak i širenje terorizma, a posebno je ukazano na značaj koji teroristi poklanjaju medijskoj pažnji. U radu je ukazano da terorističke grupe koriste masovno širenje medija i novih medijskih tehnologija da bi promovisale svoje ciljeve. Iznete su metodološke prednosti koje u radu ima novinar lokalnog ili nacionalnog emitera u situaciji kada se izveštava sa terorističkog napada. U radu je ukazano da novinar lokalnog medija ne mora biti inferioran u izveštavanju, u odnosu na velike medije, već naprotiv ima niz prednosti koje treba znalački da iskoristi u izveštavanju. U budućnosti možemo očekivati intenziviranje terorističkih napada što novinari moraju dočekati spremni da svoje konzumente informacija izveštavaju pravovremeno, objektivno i etički prihvatljivo.

Ključne reči: mediji, izveštavanje, terorizam, kriza, novinari.

\section{DEFINICIJA I POJAM TERORIZMA SA ASPEKTA MEDIJSKE PRAKSE}

Od kada se 11. septembra 2001. godine dogodio napad na „Kule bliznakinje“ u SAD, u raznim medijima od globalnih do lokalnih, širom sveta počela je sve češće da se upotrebljava reč terorizam kojom su označavani razni pokreti, grupacije ili organizacije. Novinar današnjice zbog važnosti terorizma kao medijskog fenomena mora imati solidno predznanja o teorijskim osnovama kojima se ta oblast definiše, te je važno istaći da imamo više definicija terorizma. Često citirana definicija grupe autora glasi: „Mi definišemo terorizam kao pretnju ili stvarnu upotrebu sile ili nasilja da se postignu politički ciljevi, kroz strah, prinudu ili zastrašivanje“ (Russell, Banker, \& Miller 1999: 13). Pojedini autori kao što je Daglas Kuber preuzeli su definiciju jednog novinara - komentatora koji je rekao: „Terorizam je nasilje, krivično delo, usmereno prema bezličnom cilju, izvršeno u nameri da raširi strah u okviru zajednice“ (Kuber, 1987: 499). Pravnici su dali i šire

* barovic@neobee.net 
definicije terorizma koji je determinisan kao: „Nezakonito korišćenje ili pretnja nasiljem koje budi osećanje straha jedne ili više osoba ili građanske populacije, od grupe ili pojedinca, koji su ponekad podržani od država, sa krajnjim ciljem stvarnih promena u postojećem političkom poretku države ili donošenju odluka međunarodnih organizacija ili multilateralnih korporacija“"(Schreuder, 1988: 52). Ako razmotrimo sve navedene aspekte možemo markirati nekoliko ključnih elemeneta koji su neizostavni u medijskom izveštavanju o terorizmu, a to su:

1. nasilje kao osnovni metod delovanja terorističkih organizacija i grupa;

2. strah (kao proizvod prvog elemenat), koji utiče i na samo izveštavanje i delovanje medija, jer se teroristička logika zasniva na širenju što većeg straha čak i kada nema realne opasnosti;

3. cilj terorista može biti različit od jedne do druge grupe, ali je on medijima u prvom delu krizne situacije često teško uočljiv;

4. teroristički motiv je neretko u vezi sa ciljem, ali je u osnovi vezan za ideološku koncepciju određene grupe i za medije je važan element tokom izveštavanja u kriznoj situaciji.

Nasilje je po svakoj definiciji osnov rada terorista i za medije predstavlja očekivani element i najavu da se radi o kriznoj situaciji u kojoj je „terorizam središnja tema, ako izuzmemo ratna dejstva" (Evans, 2006: 24). Krizne situacije u radu medija podrazumevaju neorganizovano nasilje (navijači, huligani, demonstranti) i organizovano nasilje (atentati, sabotaže, diverzije, napadi, kontrolisane eksplozije): „to je fundamentalna karakteristika terorizma i za medije jasan signal o kakvoj kriznoj situaciji je reč“" (Nacos, 1994:104). Ako se dogodi eksplozija plina odmah se dovodi u sumnju slučajnost ili namera da se navedena hemijska reakcija proizvede, posebno ako je nesreća bila u naseljenim delovima gradova tzv. rizične zone. Drugi, za medije koji izveštavaju u kriznim istuacijama važan momenat je strah koji možemo nazvati ,pokretnim motorom terorizma“, jer teroristi su postigli željeni efekat ako se prosečan građanin usteže da leti avionom ili razmišlja o poledicama korišćenja metroa u višemilionskim gradovima. „Ako nam predstoji let avionom, onda pretpostavljena mogućnost da je upravo taj avion izabran za otmicu ili da je u njemu postavljen eksploziv, može prouzrokovati anksiozno stanje kod potencijalnih putnika i gotovo paralisati vazdušni saobraćaj. Rat u regionu Golfa početkom devedesetih godina XX veka, pokazao je skoro potpuni kolaps avio-saobraćaja, upravo zbog straha od osvete islamskih terorista" (Srdanović, 2002:19). Zahvaljujući velikoj medijskoj pažnji teroristi mogu očekivati postizanje uspeha i realizaciju svojih ciljeva (oslobađanje saboraca, povlačenje trupa, davanje otkupa, preispitivanje važnih političkih odluka i sl.).

Mediji deluju dvojako, jer osim izveštavanja i zauzimanja vrednosnog stava o terorističkom aktu, istovremeno pružaju publicitet terorističkoj grupi, ali pojačavaju i uverenje $u$ ispravnost ideje među istomišljenicima grupacije koja je izvela akt. Teroristi imaju za cilj da pored trenutnog racionalnog i sasvim razumljivog straha stvore i ,imaginarnih strah da su sveprisutni“ i da mogu naneti udar uvek 
i na svakom mestu (Chomsky, 2001: 108). Iako je to neizvodljivo, uz (ne)svesnu pomoć medija često se imaginacija koju priželjkuju teroristi realizuje, te se stvara opšta konfuzija i raprostranjen osećaj opšte nesigurnosti.

Treći element je cilj terorista koji je za medije u kriznim situacijama često važan deo izveštaja, ali osim organa bezbednosti i vladinih službi mediji retko odmah saznaju za ciljeve i zahteve terorista u početku krize. Motiv za delovanje je usko povezan sa ciljem i zavisi od vrste grupe ili organizacije koja vrši terorističke akte (Cooley, 2001: 72). Jedan od polaznih elemenata je i podela terorističkih organizacija koje se (prema Rusellu et al.) mogu razvrstati na:

1. nacionalističko - etničko - separatističke grupacije koje za cilj imaju autonomne etničke nacionalne države ili se bore za nezavisnost;

2. ideološko-religijske grupe koje ne moraju uvek imati vidljivu idejnu komponentu u delovanju;

3. grupe koje su povezane motivacijom kao što je recimo nihilizam;

4. grupe koje deluju na osnovu interesnog povezivanja u cilju političkog afirmisanja. (Rusell, Banker \& Miller 1999: 31-32).

Sa medijskog aspekta važno je da napravimo jasnu podelu organizacija jer u kriznim situacijama od vrste organizacije zavisi i kako će teći kriza, tj. da li će biti oslobođeni taoci (islamski teroristi to retko rade), da li je moguć otkup (taj postupak praktikuju ideološke grupe zbog novca za dalje delovanje), da li postoje pregovori, kakav je zahtev terorista, uz napomenu da svaka teroristička akcija nosi specifikum određene organizacije.

Druga grupacija u koju ulaze ideološki orjentisani teroristi je nakon propasti istočnog bloka u opadanju i ona je za medije zanimljiva kao reperna tačka za istorijske paralele. U nju spadaju: „Crvene brigade“ i „Frakcija Crvene armije“. To su uglavnom levičarski ili desničarski ekstremni elementi koji su inspirisani marksističkom, maoističkom, lenjinsitičkom, nacističkom ili fašističkom ideologijom. Postoje razne grupacije u Aziji i Južnoj Americi koje inspirisane levičarskom ideologijom vrše terorističke akcije ali se baziraju i na aktivnoj gerilskoj brobi protiv vladajućih režima (najpoznatiji je kolumbijski FARC - „Revolucionarne oružane snage Kolumbije“). Treća grupa koja je zasnovana na motivaciji uglavnom je malobrojna i nema većih akcija tako da tog vida terorizma nema mnogo u medijskoj praksi. Tih slučajeva terorizma bilo je u SAD (grupa „Symbionese Liberation Army“) i početkom 70-ih godina u Nemačkoj, kada je psihijatar Huber sa suprugom ubedio pacijente da je društvo od njih napravilo bolesne ljude i da se zato moraju osvetiti i uništiti društvo (Rusell, Banker \& Miller, 1999: 31-32).

Četvrti vid terorizma su grupe koje se uzajamno interesno povezuju u cilju političke afirmacije, a uglavnom su to pojedinci frustrirani mirnim političkim delovanjem i stoga pribegavaju nasilju. To su male grupacije koje su nastale nakon cepanja levičarskih stranaka, ali je njihova ideologija u pozadini interesa za političkom važnošću i privlačenjem pažnje medija koji od njih čine „heroje dana“. 
Ovoj podeli treba dodati i verski element koji do izražaja dolazi od 2001. godine, a oličen je u delovanju „Al Kaide“. Sa medijskog aspkta taj model terorizma je u ekspanziji i preti da po intenzitetu i snazi akcija nadmaši sve poznate oblike terorizma. U sukobu na Bliskom istoku za domaće novinare je značajno da uoče razliku između ekstremnih krila „Fataha“ i „Hezbolaha“ kao i raznih šiitskih milicija koje su pod kontrolom Irana, jer sve te organizacije imaju kapacitete, kadrove i logistiku za veće ili manje terorističke akte. Nije samo islamski terorizam inspirisan religijom već i razne verske grupacije imaju mogućnost za terorističko delovanje, za šta ima primera u medijskoj praksi npr. u tokijskom metrou marta 1995. godine verska grupa „Aum Šinrikjo“, bacila je otrovni gas sarin: „od posledica trovanja umrlo je 12 osoba a povređeno je preko 5.500 putnika“" (Luković, 2000: 261-263).

\section{MEDIJI I TERORIZAM}

Pred medijima i novinarima kada se nađu u kriznim situacijama kao što je bacanje bombe ili neki oružani okršaj često stoji otvoreno pitanje: koja je razlika između kriminala i terorizma? Teoretičari različito tumače pojedine slučajeve terorizma, ali se slažu u tome da je razlika pre svega u političkoj motivaciji koja stoji iza terorizma, dok je za kriminal uglavnom vezan čist materijalni motiv, ako se isključi patološka sklonost krimogenim radnjama (Asmus, 2002: 151). Novinar na osnovu političkog motiva koji je na manje ili više vidan način prisutan u jednom aktu, može prepoznati (ne)postojanje terorizma kao delovanja koje se ispoljava na razne načine i kroz različite forme.

Kao prvi savremeni akt terorizma sa aspekta medijskog izveštavanja sa kriznih situacija, možemo markirati otmicu izraelskog aviona na liniji Rim - Tel Aviv koja je izvršena 23. jula 1968. godine. Tada su mediji izvestili o toj kriznoj situaciji sa svim elementima koje danas prepoznajemo u štampanim i elektronskim medijima, sa tom razlikom da tada nije bilo interneta. Otmicu je izveo „Narodni front za oslobođenje Palestine" $\mathrm{i}$ bio je to prvi akt međunarodnog terorizma kako su ondašnji mediji ocenili tu kriznu situaciju (Russel, Banker \& Miller, 1999: 6). Novinari-komentatori i analitičari uočili su da se mediji suočavaju sa modernim terorizmom u sve većoj meri i da često nemaju spremne i obučene izveštače, reportere, terenske novinare, koji će dobrim poznavanjem tematike moći da pravovremeno odgovore tom specifičnom izazovu. Postoji mnogo elemenata koji utiču na nastanak terorizma, ali za novinare i medije važna je činjenica da je terorizam kao relativno nov fenomen nastao iz pet osnovnih razloga:

1. masovna upotreba civilnog vazdušnog saobraćaja;

2. bujanje nacionalističkih i separatističkih pokreta, koji su neretko tajno pomagani od raznih država ili državnih struktura (tajnih službi, vojnih struktura i sl.);

3. širenje radikalnih verskih učenja;

4. eskalacija sukoba u kriznim regionima;

5. razvoj medija, masovnih komunikacija i tehnoloških dostignuća. 
Terorističke grupe sve umešnije zloupotrebljavaju medije, mnoge imaju svoje portparole koji daju izjave da li je njihova organizacija preuzela odgovornost za napad, a sve veći broj terorističkih akata i egzekucija snima se kamerom i putem interneta emituje. Mediji su teroristima uvek potrebni i bez njih bi većina napada koje izvode bila zanemarljiva, jer osim malog broja žrtava i razaranja sa globalnog stanovišta, ta nedela bez medijskog pritiska ne bi imala većeg uticaja na donošenje političkih odluka, državnu politiku i strategijske planove.

Svakako je važno istaći da nesavesnim ili tabloidnim izveštavanjem u kriznim situacijama mediji mogu (ne)svesno doprineti nekom od ciljeva terorista, ali je pritisak na vladu da teroristima popusti ili ne popusti, pravi zadatak medija kao čuvara javnog interesa. Ako mediji imaju ulogu „pasa čuvara“ javnog interesa, oni moraju jasno markirati prioritete koji neće biti u koliziji sa profesionalnim i etičkim izveštavanjem. U vreme terorističkih napada mediji se nalaze u specifičnoj situaciji koju mogu pratiti kao lokalni, regionalni, pokrajinski, nacionalni ili globalni. U tom segmentu ne smemo zaboraviti i specijalizovane medije (štampu) i elektronske specijalizovane emisije koje se bave terorizmom (najpogodnije za praćenje te vrste krizne situacije). Američki „CNN“ je počeo da emituje program bez prekida 24 sata, marta 1981. godine nakon neupešnog atentata na Ronalda Regana, a „danas imamo preko 110 medijskih informativnih programa koji emituju celodnevni program“" (Dobbins, 2005: 17).

Prva pretpostavka jeste da će dobro opremljen globalni medij, najbolje pratiti neku kriznu situaciju koja podrazumeva terorizam, što je posmatrano sa medijskog aspekta samo uslovno tačno. Ako uzmemo klasičan teroristički čin kao što je otmica talaca, tada će novinar lokalnog medija na terenu gde se dogodio napad biti u velikoj prednosti u odnosu na internacionalni ili nacionalni medij. Polazni elementi koji ukazuju da novinar lokalnog lista ili rtv stanice ima prednost u izveštavanju sa terorističkog napada kao oblika krize su sledeći:

1. on/ona su na licu mesta i na izvoru informacija;

2. poznaju teren i lokalne organe vlasti koji su prvi u rešavanju situacije;

3. prvi će saznati identitet otetih osoba;

4. imaju bolja obaveštenja nakon prvog (udarnog) dela krizne situacije;

5. lakše prati kriznu situaciju (sa bolje pozicije, lakše se kreće, bolje se orjentiše);

6. ima osnovnu logistiku;

7. ima primarnu poziciju za praćenje krizne situacije dugog trajanja;

8. iz lokalnih izvora će prvi imati najsvežije informacije jer poznaju one koji upravljaju situacijom (načelnika policije, predsednika opštine, komandira vatrogasne brigade, direktora vodovoda, policijace koji obavljaju kordoniranje, radnike hitne pomoći).

Sve navedene prednosti idu u prilog novinaru lokalne medijske kuće, ali kada na hipotetičku kriznu situaciju dođe novinar/ka nacionalne ili internacionalne mreže njihove prednosti su sledeće: 
1. imaće dotok informacija iz više izvora;

2. imaju veliku gledanost/čitanost i ako novinar/ka lokalnog medija želi da plasira neku informaciju u širu javnost mora ići preko nje/njega;

3. poseduju bolje tehničko-tehnološke kapacitete i sredstva veze;

4. autoritetom svoje medijske kuće imaju bolje pregovaračke pozicije sa organima vlasti;

5. ako je poznat novinar/ka postoji mogućnost da dobije ekskluzivno pravo da sa posebnim odredom priđe bliže mestu hipotetičke otmice odakale će napraviti snimak/fotografiju;

6. imaju mogućnost korišćenja brzih sredstava transporta (helikopter, posebna vozila);

7. imaju veliki logistički tim koji pruža tehničku podršku u radu (asistenti, novinari reporteri, vozači, mobilna tehnika).

$\mathrm{Na}$ osnovu iznetih elemenata možemo zaključiti da je u radu ukazano da novinar/ka lokalnog medija ne mora biti inferioran/a u izveštavanju, u odnosu na velike medije, već naprotiv ima niz prednosti koje treba znalački da iskoristi u izveštavanju. Možemo konstatovati da je bez obzira na to da li je medij lokalni ili nacionalni, presudnu ulogu igra ljudski faktor koji je najvažniji činilac u izveštavanju sa kriznih situacija, posebno sa veoma stresnih incidenata koji su posledica terorističkog napada, otmice, postavljanja bombe.

Mediji veoma brzo stižu na mesto krize kada se dogodi teroristički akt. Od 11. septembra 2001. godine terorizam je postao veoma važna tema svih visokotiražnih medija sa posebnim akcentom na zapadne zemlje gde je to sveprisutan i neiscrpan izvor novinarskih članaka, kolumni, reportaža, specijalnih emisija, živih gostovanja, direktnih uključenja. U toj trci za gledanošću/čitanošću/slušanošću, dešavaju se i preterivanja, te mediji ,podgrevaju atmosferu“ pred godišnjice velikih terorističkih napada u prošlosti, pred velike praznike i stiče se utisak da je u medijima veoma bitno pisati i pričati o terorizmu koji jeste realna opsanost, ali nije univerzalna tema za popunjavanje praznog prostora u medijima. Terorizam se u pojedinim medijima olako prihvata kao multipraktično sredstvo za podizanje gledanosti i tiraža, ali većina redakcija nije dovoljno spremna da odgovori na potrebu izveštavanja sa takvih kriznih situacija kada su ne samo ugroženi životi onih koji su meta terorističkog napada već i novinara/ke koji mogu postati žrtve.

\section{POLAZNI ELEMENTI ZA IZVEŠTAVANJE}

Rad novinara u kriznoj situaciji kao što je teroristički akt umnogome je kompleksan i zavisi od više faktora koji variraju od jedne do druge krize, a u radu su markirani polazni elementi za izveštavanje u kriznim situacijama. Najveći broj kriznih situacija koje tretiraju terorizam, po procenama kompetentnih stručnjaka, svetski mediji tek treba da očekuju, ,jer taj fenomen je u ekspanziji“ (Srdanović, 2002: 27). 
Da bi korektno izveštavao u toku i posle terorističkih napada novinar mora da ispunjava nekoliko opštih uslova:

1. Mora biti dobro informisan pre odlaska na teren;

2. treba da bude dobro pripremljen za tu vrstu kriznih situacija;

3. neophodno je da poseduje znanje za brzu selekciju prioritetnih informacija;

4. bitno je da ima korektnu moć procene (situacije, broja žrtava, intenziteta napada);

5. mora biti snalažljiv i spreman da efikasno dođe do izvora informacija i sagovornika.

Teroristički napad je veoma teško predvideti, jer ako to ne mogu da učine bezbednosne strukture najvećih država, sigurno je da ne mogu ni mediji, ali postoje određene pripremene radnje koje novinar može obaviti. Reporter koji se bavi kriznim situacijama mora dobro poznavati organizacije i grupacije koje deluju u regionu koji on pokriva, a upražnjavaju nasilje kao oblik političkog delovanja (Kepel, 2002: 139). U sklopu priprema dobro je upoznati taktiku, namere, frakcije, ideologiju i lidere organizacije koja je najaktivnija u određenoj državi.

Neophodno je sistematično znanje o verskom, političkim i nacionalnom sastavu određene terorističke grupacije, a uz konsultovanje stručnjaka moguće je stvoriti dobru analitičku pretpostavku za moguće scenarije koje određena grupa preduzima u pojedinim slučajevima2. Ako se sprovedu neke političke odluke za očekivati je da terorističke organizacije preduzmu korake koje najavljuju ili za koje se potajno spremaju, što je čest primer u kriznim regionima kod nas i u svetu. „Pored dobre informisanosti i faktografskog pristupa u izveštavanju, ono što novinar može da uradi u sklopu priprema za kriznu situaciju jeste da se dobro opremi sredstvima koja mu u datom trenutku mogu biti od značajne pomoći tokom izveštavanja“" (Barović, 2011: 121). Svaki reporeter može imati spremne i proverene sisteme veze sa kolegama, redakcijom, link vozilom. Za krizne situacije kratkog trajanja a posebno dugog i konstantnog trajanja neophodna je konzervirana hrana, prva pomoć, baterijske lampe, a po potrebi je poželjno nabaviti pancirni prsluk i zaštitni šlem (sa oznakom „press“). Pre krizne situacije takva priprema često izgleda izlišna ali je u praksi takav stav višestruko demantovan, jer dobra praktična ali i teorijska priprema umnogome olakšava rad na terenu.

Nakon prve informacije o terorističkom udaru, važno je dobro odreagovati i organizovati rad na terenu ali i u desku. Pripremljene redakcije imaju timove koji su uhodani u tom poslu, ali ako nije formirana grupacija za krizne situacije najbolje je da urednik odredi tim koji izlazi na teren i one koji ostaju u redakciji sa ciljem da koordiniraju i organizuju rad u desku. Tim koji odlazi na teren ako je televizija u pitanju, mora imati dobru logistiku (mobilnu tehniku sa pratećom

\footnotetext{
http://www.rts.rs/page/stories/ci/story/2/\%D0\%A1\%D0\%B2\%D0\%B5\%D1\%82/1332974/\%D0\%90\%D0\% $\mathrm{BB}+\% \mathrm{D} 0 \% 9 \mathrm{~A} \% \mathrm{D} 0 \% \mathrm{~B} 0 \% \mathrm{D} 0 \% \mathrm{~B} 8 \% \mathrm{D} 0 \% \mathrm{~B} 4 \% \mathrm{D} 0 \% \mathrm{~B} 0 \% 2 \mathrm{C}+\% \mathrm{D} 0 \% \mathrm{BF} \% \mathrm{D} 0 \% \mathrm{~B} 0 \% \mathrm{D} 1 \% 86 \% \mathrm{D} 0 \% \mathrm{BA} \% \mathrm{D}$ $0 \% \mathrm{~B} 5+\% \mathrm{D} 0 \% \mathrm{BD} \% \mathrm{D} 0 \% \mathrm{~B} 5 \% \mathrm{D} 0 \% \mathrm{BF} \% \mathrm{D} 0 \% \mathrm{BE} \% \mathrm{D} 1 \% 81 \% \mathrm{D} 0 \% \mathrm{BB} \% \mathrm{D} 1 \% 83 \% \mathrm{D} 1 \% 88 \% \mathrm{D} 0 \% \mathrm{BD} \% \mathrm{D} 0 \% \mathrm{~B}$ E\%D0\%BC+\%D1\%82\%D0\%B5\%D1\%80\%D0\%BE\%D1\%80\%D0\%B8\%D1\%81\%D1\%82\%D0\%B8.html
} 
opremom) i najbolje je ako je sastavljen od mlađih novinara, jer u toj vrsti krizne situacije važan faktor predstavlja ne samo radna energija već i fizička kondicija i izdržljivost. Po pristizanju na mesto krize, vođa novinarskog tima mora odabrati najbolju moguću poziciju za izveštavanje, (što nije veliki problem ako je u pitanju radio ili štampani medij), posebno ako je televizijska ekipa na mesta krize. Za tv je bitna slika, jer ako govorimo o talačkoj krizi nećemo mnogo uraditi sa belim zidom iza leđa (isti ili čak i bolji zid možete naći u studiju). Pozicija se uvek mora birati u dogovoru sa osobama iz policije koje komanduju kordoniranjem položaja oko mesta terorističkog napada, zgrade u kojoj su taoci i sl. Veoma je važno, što su naveli i iskusni američki novinari, da imate adekvatnu sliku u foto-aparatu i dobru pozadinu na displeju kamere. U slučaju „Kula bliznakinja“ u Njujorku to je bilo lako izvodljivo ali je zato u reonu Pentagona, koji je dobro kordoniran bilo teško napraviti dobru sliku. To je rešeno pravljenjem takvog vizuelnog plana u čijoj pozadini se video gust dim, snimana su kola hitne pomoći ili je snimatelj ,„svenkovao", dok je novinar razgovarao sa sagovornicima. U slučaju da policija zabranjuje bilo kakvo snimanje i prilaženje mestu napada, što nije redak slučaj kada je terorizam u pitanju, postoji mogućnost da se u živom uključenju iz reportažnih kola ili iz režije, dok traje uključenje, puštaju takozvane „pokrivalice“, kadrovi koji su ranije snimljeni, a oslikavaju ono o čemu novinar u tom trenutku (,izlazu“) govori.

Pored uzimanja dobre (ili najbolje moguće) pozicije predstavnik medija mora poštovati tempo uključenja u radijski ili TV program koji je dogovoren sa urednikom. Ako ne može da nađe adekvatnog sagovornika novinar/ka na licu mesta može naći nekoga od spasilaca ili svedoka koji će ispričati šta je video.

Novinari koji ostaju u redakciji osim što se angažuju na radu u desku moraju da „pokrivaju“ mnogobrojne brifinge i pres konferencije koje u navedenim situacijama organizuju razne državne službe (državni upravni organi, policija, vojska, vatrogasci). Kada je terorizam u pitanju ako se ide na duži terenski rad bitno je poštovanje instrukcija od strane bezbednosnih organa, jer nije jednostavno samostalno (ili sa ekipom), kretanje po nesigurnom području, uz napomenu da je novinar - vođa tima odgovoran za sve članove ekipe (Stempel, 2003: 76).

Ako je teroristički akt koncentrisan na jedno mesto, tada je ekipa usresređena na tu lokaciju, ali ako imamo više jednovremenih napada tada se pristupa takozvanom sektorskom radu. Vođa tima (ili urednik) podeliće novinare sa zadatkom da prate dve, tri ili više sektora i zadužiće jednog novinara da njihov rad koordinira i objedinjuje $u$ jedan izveštaj (ili u više odvojenih u zavisnosti od vrste emisije, programskih zahteva, prostora u dnevnom listu). Sektorski rad je mnogo bolji zato što neće doći do preplitanja u radu dva novinara iz iste medijske kuće, a veća je mogućnost za sticanje sveobuhvatne slike o kriznoj situaciji u celini.

Terorizam je specifičan po ustezanju nadležnih da daju u prvom talasu krizne situacije brze, tačne i pravovremene informacije, i zato se dešava da novinari pribegavaju alternativnim rešenjima. Policija na početku krize retko daje izjave ali je moguće nezvanično saznati neke podatke (broj terorista, šteta od bombe, žrtve, broj talaca), od strane izvora - pojedinih pripadnika službe bezbednosti, a najčešće su 
dobri izvori informacija ljudi iz vatrogasnih brigada ili hitne pomoći, koji preko radio veze imaju dobre podatke.

Kada dođe do željenih podataka pred novinara se postavlja pitanje koji su istiniti, šta je delimično tačno, kom izvoru poverovati? Tu dolazimo do sistema selekcije informacija, što je u izveštavanju sa terorističkih napada veoma važno ali i složeno, jer su česte (ne)namerne dezinformacije i poluistine npr. u prvom trenutku na Pentagon je navodno pao helikopter kako je prenela većina medija, bilo je 800 mrtvih, za „Kule bliznakinje“ je takođe bilo velikih oscilacija u broju nestalih (Stempel, 2003: 79). Najbolja selekcija informacija u kriznoj situaciji kao što je terorizam, jeste poređenje više izvora, a kada je to nemoguće do izražaja dolazi moć procene koju novinar zasniva na statistici, mogućem broju ljudi, pretpostavci (Nacos, 1994: 51). Poznavanje prilika ali i osećaj za realnost i profesionalna pribranost u trenutku odluke utiču na selekciju informacija. Najbolje je u kriznoj situaciji posavetovati se sa ekspertom ili stručnim licem koje radi u nekoj naučnoj instituciji ili nevladinoj organizaciji. U svakom slučaju bolje je biti umeren $u$ proceni žrtava nego preterivati bez osnova, jer je lakše „,na osnovu novih saznanja nakon napada“ povećati broj poginulih nego pisati demanti. „Reakcije novinara nikada neće biti profesionalne ako se opredeli za empatičku teoriju i okrene se emocijama u kriznoj situaciji koja ni predstavnike medija neće ostaviti ravnodušnim, ali je nedopustivo javno manifestovati svoje emotivno stanje“ (Barović, 2008: 11). Svakako je saučestvovanje u bolu za poginulim umesno, ali je svaka lamentacija nad sudbinom unesrećenih prekoračenje profesionalnih normi i odnosa prema kriznoj situaciji.

Ako krizna situacija preraste u krizu dugog trajanja, tada vođa ekipe prelazi u rad u smenama, jer jedan tim može da medijski iznese samo prvi talas krizne situacije, a nakon toga dolazi do zamora ljudskih resursa. Potrebna je smena i minimalan odmor, te se vrše razne neophodne mere: povlačenje novinara iz drugih rubrika, ispomoć iz drugih redakcija, skraćivanje odmora. U izveštavanju sa terorističkih napada najpoželjnije je pratiti situaciju sa udaljenosti koju dozvoljavaju organi bezbednosti, i nije preporučljivo preduzimati samostalne korake. Svi članovi tima moraju razumeti i u celosti shvatiti ozbiljnost situacije te je neophodno u improvizovanoj redakciji povremeno organizovati interne brifinge na kojima će osim razmene informacija svi članovi tima biti obavešteni o tempu rada u narednih 6 sati. Poželjna tempo brifinga je na svakih 6 do 8 sati kada se okuplja ceo tim (osim onih koji trenutno rade uključenje, montažu, snimanje).

Terorizam je često krizna situacija slična ratnom izveštavanju u kom je život reportera neretko ugrožen, i tu dolazi do izražaja solidarnost novinara (to posebno mora doći u prvi plan kada je u pitanju matična kuća) (Evans, 2006:16). Bez obzira na sve izražene simpatije ili antipatije koje na žalost u medijima postoje, na terenu se mora pokazati maksimalna solidarnost, poštovanje i pružanje svake profesionalne pomoći kolegi novinaru ili drugom saradniku.

U kriznim situacijama često dolazi do izražaja lična inventivnost i snalažljivost izveštača kada nema dovoljno informacija, a lucidan reporter brzo će uočiti neki 
propust, otkriće zanimljivog sagovornika, raspitivaće se kod policajca, predstavnika gradskih vlasti, poznanika iz civilne zaštite ili hitne pomoći. Mlađi novinari mnogo toga mogu naučiti i od starijih kolega koji ne moraju da rade na njihovom mediju, a sve greške treba preduprediti vežbanjem (za ,živa uključenja“) i treba izbegavati improvizacije, kad god je to moguće.

U izveštavanju sa terorističkih napada presudan faktor je psihička stabilnost izveštača i njegova spremnost da se izbori sa velikim profesionalnim ali i ljudskim pritiskom jer kada se radi o životima, teško je ostati potpuno smiren i koncentrisan na rad, usled velike koncentracije stresa. „Ljudi koji rade u medijima, izuzimajući njihov životni stil, uvek hodaju na liniji između brige o sebi i stresa koji izaziva probleme. Pored normalnog visokog stresa na poslu, ljudi iz medija su izloženi direktnoj traumi kada su u jednu ruku svedoci nasilja i tragedija i u drugu ruku doživljavaju povratnu traumu kada su izloženi tragediji tokom intervjuisanja žrtava i izvršilaca, pri čemu konstantno teraju sebe da zaborave tu sliku“ (Ross, 2003:74).

\section{ZAKLJUČAK}

U zaključnom razmatranju, treba navesti primer američkih novinara koji su neprekidno tokom prvog talasa napada od 11. 09. 2001.godine, izveštavali i išli „uživo“ u program sa maksimalnom pripremljenošću, prisebnošću i koncentracijom vrednom poštovanja u takvim uslovima (Greste, 2009:14). Kao primer dobre prakse treba istaći i hrabrost ruskog kolege sa „NTV“-a koji je ušao u moskovsko pozorište „Dubrovka“ koju su držali teroristi sa ogromnim brojem talaca, i tamo je uradio intervju sa vođom terorističke grupe3.

Imamo niz drugih primera koji svedoče o maksimalnom poštovanju profesije i javnog interesa prilikom izveštavanja sa terorističkih napada. To govori da su krizne situacije tog tipa specifične i zahtevaju novinare spermne da odgovore na najveća iskušenja, jer taj deo posla može da radi samo pripremljen i odlučan profesionalac.

Treba naglasiti da o terorizmu, kolumne često pišu eksperti iz navedene oblasti, jer kod nas nema dovoljno novinara - specijalista; taj problem u srpskim medijima uglavnom tretiraju urednici koji obrađuju vojna pitanja. U kratkom roku možemo očekivati usko profilisanje novinara koji će pratiti tu tematiku, i to zbog činjenice da će ta krizna situacija biti u narednom periodu u porastu. U završnom razmatranju navedene problematike, naglašavam da je dužnost novinara koji prati navedenu kriznu situaciju da u potpunosti ispoštuje propisani etički kodeks, ali je poželjno i da obrati pažnju na opšte prihvaćene moralne norme. Terorizam je moguće posmatrati sa više različitih aspekata ali je u radu na terenu važno poštovati profesionalne norme ponašanja, a objektivnost i faktografski pristup problematici, jedini su ispravan put u izveštavanju sa kompleksne krizne situacije kao što je terorizam.

http://www.nin.co.rs/2002-10/31/25708.html 
Iskustva stranih novinara neretko govore da su predstavnici medija na meti raznih terorističkih grupa i totalitarnih režima ( „Talibani hapse novinare“, Dnevnik, 29.09.2001.). Neretko se dešava da novinari koji istražuju aktivnosti terorista i pišu o njihovoj organizaciji, članovima, planovima ili namerama budu meta napada određenih organizacija. Teroristi ne biraju ni vreme ni mesto da se obračunaju sa svojim neistomišljenicima, koji su po njihovom sudu zaslužili da budu napadnuti („Ubijen novinar“, Dnevnik, 30.09.2001.). Surova realnost poslenika javne reči sastoji se iz opasnosti da reporter koji izveštava sa neke od kriznih situacija postane predmet pretnji, napada ili likvidacije. Navedene činjenice ni u kom slučaju ne smeju uplašiti buduće izveštače sa kriznih situacija, uključujući i terorizam već ih trebaju utvrditi u stavu da je odbrana javnog intersa i slobode javne reči jača od svake pretnje i napada. Specijalizacija za izveštavanje sa terorističkih napada preporučljiva je posebno mlađim novinarima i onima koji preferiraju terenski rad, jer taj posao zahteva maksimalan psihički i fizički napor, na koji ne može odgovoriti nespreman i nepripremljen pojedinac. Da je medijski rad naporan i često nezahvalan nećemo posebno isticati, ali istovremeno je izveštavanje sa terorističkih akata poseban izazov na koji se mogu odlučiti samo najsmeliji i najobučeniji novinari kojima je profesija iznad udobnosti svakodnevnog života.

\section{LITERATURA}

Asmus, R. (2002). Opening NATO s Door. New York: Columbia University Press.

Barović, V. (2008). Izveštavanje u kriznim situacijama i objektivnost, Link, 60-61, 11.

Barović, V. (2011). Objektivnost, novinarska etika i izvještavanje u kriznim situacijama. U:

Viktorija Car (2011). Medijske studije (str. 118-126), vol. 2 (2011) 3-4. Sveučilište u Zagrebu.

Beres, L. R. (1988). Terrorism and Global Security: The Nuclear Threat. Colorado: United Press.

Chomsky, N. (1988). Culture of Terrorism. South End Press.

Chomsky, N. (2001). 9-11. New York: Seven Stories Press.

Cooley, J. (2001). Unholy Wars: Afghanistan, America and international terrorism. New York: Pluto.

Dnevnik, dnevni list izlazi u Novom Sadu od 1942. godine

Dobbins, J. (2005). RAND History of Nation - Building. New York: Seven Stories Press.

Evans, H. (2006). War Stories - Reporting in the Time of Conflict From the Crimea to Iraq.

Boston-London: Bunker Hill Publisihing.

Friedlander, A. R. (1977). The Origins of International Terrorism. New York: Harcourt Brace. Greste, P. (2009). Drinking Tea with Terrorists. Global Journalist, Volume 15, Number 2, 12-15. Kepel, G. (2002). Jihad, expansion et declin de 1 islamisme. Paris: Gallimarde.

Kuber, D. (1987). A Sewing Lesson in Political Offence Determinations, Stitching - Up the International Terorists. Comparative Law Review,490-503.

Luković, D. Z. (2000). Verske sekte,Beograd: Draganić.

Nacos, L.B. (1994). Terrorism \& the Media - From the Iran Hostage Crisis to the Oklahoma City Bombing. New York: Columbia University Press.

Ross, G. (2003). Beyond the Trauma Vortex: The Media's Role in Healing fear, terror and Violence. Berkeley, California: North Atlantic Books. 
Russell, A. C, Banker, I. L., \& Miller H. B. (1999). Out- inventing Terrorist, Terrorism: Theory and Practice. Colorado: United Press.

Schreuder, W. (1988). International Legal Measures Against Terrorism. Leiden Journal of International Law, 41-62.

Snyder, L. L. (1998). Encyclopedia of the Third Reich. Hertfordshire: University of Hertfordshire Press.

Srdanović, R. B. (2002). Međunarodni terorizam, politički delikt, ekstradicija. Beograd: Službeni list SRJ.

Stempel, H.G. (2003). Media and Politics in America. Santa Barbara: Santa Barbara Univerity Press.

http://books.google.rs/books?id=hoLcmxTTYWcC\&printsec $=$ frontcover\&hl $=$ sr\&source $=\mathrm{g}$ bs_ge_summary_r\&cad $=0 \# \mathrm{v}=$ onepage $\& \mathrm{q} \& \mathrm{f}=$ false

http://www.nin.co.rs/2002-10/31/25708.html

Vladimir Barović

\title{
POLAZNI ELEMENTI ZA MEDIJSKO IZVEŠTAVANJE \\ O TERORIZMU KAO OBLIKU KRIZNE SITUACIJE
}

\begin{abstract}
REZIME
Medijsko izveštavanje na temu terorizma u poslednjoj deceniji je intenzivirano zbog naglog porasta aktivnosti različitih terorističkih organizacija i grupa. Da bi novinari razumeli problem terorizma, potrebno je definisati taj fenomen sa medijskog aspekta i pojasniti podelu terorističkih organizacija, kao i osnovne uzroke zbog kojih iste postoje i šire se. U radu su navedeni prvi napadi koje možemo nazvati terorističkim a praćeni su od strane medija; zatim su determinisani polazni elementi u pripremi novinara koji treba da izveštava sa te vrste krizne situacije. U polazne elemente spadaju fundamentalno predznanje i podaci koji mogu uticati na bezbednost izveštača i njegovog medijskog tima, što sugeriše da se teorijski moraju uobličiti profesionana znanja i veštine pre izlaska na mesto krize. Iznete su metodološke prednosti koje u radu ima novinar lokalnog ili nacionalnog emitera u hipotetičkoj situaciji kada se izveštava sa terorističkog napada. U radu je dokazano da novinar lokalnog medija ne mora biti inferioran u izveštavanju, u odnosu na velike medije, već naprotiv ima niz prednosti koje treba znalački da iskoristi u izveštavanju. Jedan od bitnih elemenata je faktor psihičke stabilnosti, što je ključan momenat za pravovremeno, objektivno i etički prihvatljivo izveštavanje sa terorističkih napada kao oblika visokorizičnih kriznih situacija. Izveštavanje sa terorističkih napada, prema predviđanju stručnjaka u bližoj budućnosti može biti intenzivirano i zbog navedenih razloga od ključne važnosti je da imamo obučene i spremne izveštače, koji će na bezbedan i profesionalno prihvatljiv način umeti da obave novinarski posao.
\end{abstract}

Ključne reči: mediji, izveštavanje, terorizam, kriza, novinari. 
Vladimir Barović

\title{
BASIC ELEMENTS FOR MEDIA REPORTING ON TERRORISM AS A FORM OF CRISIS SITUATION
}

\begin{abstract}
SUMMARY
Media reporting on terrorism has been intensified in the last decade due to a sharp increase in the activities of different terrorist organizations and groups. In order for journalists to understand the problem of terrorism, it is needed to define this phenomenon from the media aspect and explain the division of terrorist organizations as well as the basic causes of their existence and expansion. This paper has set forth the first attacks that can be regarded as terrorist ones reported by the media. Then, there have been determined the basic elements for the preparation of a journalist who is due to report on the given type of crisis situation. The basic elements include fundamental background knowledge and information that can affect the safety of the reporter and their media team, which suggests that professional knowledge and skills need to be theoretically formulated before visiting the scene of the crisis situation. There have been listed methodological advantages that a journalist of a local or a national broadcasting company has in a hypothetical situation when reporting on a terrorist attack. It has been proved that a journalist of local media is not necessarily inferior to larger media in their reporting. What is more, there are a number of advantages that should be skillfully used by journalists of local media in their reporting. An important element is psychological stability that is a key factor for timely, objective and ethically acceptable reporting on terrorist attacks as a form of highly risky crisis situations. According to experts' predictions, reporting on terrorist attacks can be intensified in the near future. For the given reasons, it is of key importance to have trained and prepared reporters who will be able to do a journalist's job in a safe and professionally acceptable manner.

Key words: media, reporting, terrorism, crisis, journalists.
\end{abstract}

